\title{
A Social Benefit-Cost Analysis of Mandatory Deposits on Beverage Containers*
}

\author{
Richard C. Porter \\ Department of Economics, University of Michigan, Ann Arbor, Michigan 48109
}

Received February 2, 1978

\begin{abstract}
This paper presents a social efficiency analysis of mandatory deposits on beverage containers. Five kinds of resource effects are identified, evaluated and added up: (1) litter (both pickup and "eyesore" costs); (2) solid waste collection; (3) container costs; (4) production and distribution costs; and (5) consumer convenience. It is shown that the desirability, on efficiency grounds alone, of mandatory deposits is not indisputable; it depends critically on one's evaluation of (1) the average value of the time it takes consumers to return empty containers and (2) the average value of the "eyesore" benefit of a dramatically reduced (i.e., by around three-fourths) volume of beverage container litter.
\end{abstract}

\section{INTRODUCTION AND SUMMARY}

On October 1, 1972, mandatory deposits on beer and soft drink containers were initiated in Oregon. Since then, other states have considered such legislationsome adopting, some rejecting. In each case there has been a massive outpouring of analysis and opinion, but to my knowledge there has never been a basic social benefit-cost assessment of mandatory deposits. It is the purpose of this paper to remedy this deficiency.

Mandatory deposit means just that: each purchaser of a beer or soft drink beverage must post a deposit which is refunded only if the container is returned. Needless to say, this places a burden of disposal of nonrefillable containers on the retailer/bottler and leads to a dramatic increase in the use of refillable bottles.

By a social benefit -cost evaluation of a policy change, I mean a quantitative summation of its anticipated impacts on consumption benefits and resource costs (properly signed and present valued). Previous attempts at a benefit-cost appraisal of mandatory deposits have failed on two counts: (i) transfers have been included as if they were social benefits or costs; e.g., changes in prices of beverages, tax collections, consumer deposit losses on unreturned containers, and the profits and book values of assets in bottle-making, bottling, and retailing firms ${ }^{1}$; and (ii) goals other than economic efficiency have been introduced,

* I am indebted to many members of Economics 471 (1976 and 1977) for ideas and insightful critieisms of an early draft.

${ }^{1}$ See, for examples, Branch [4]; Lowry et al. [22]; Maillie [23]; Murphy [25]; and Savage and Richmond [29]. The "bcst" example of mixing transfers with resources is the concluding paragraph of Maillie's summary (p. 2):

Considering that 1969's known public expenditures for litter piekup . . . on . . . roads totaled just $\$ 33.4$ million, and national collection and disposal costs of beverage container 
especially concern for income distribution and employment. All of these are important considerations, but they should be complementary to, and not included in, an efficiency-oriented social benefit-cost analysis. ${ }^{2}$

The analysis here is an appraisal of Michigan's "bottle law" from the viewpoint of the welfare of Michiganders. Considered in detail (in Sections 3-7) are the five principal sources of changes in social benefits and costs: (i) litter (both pickup and "eyesore" costs); (ii) solid waste; (iii) containers; (iv) production and distribution; and (v) consumer convenience. For the first three, mandatory deposits result in reduced social costs (or increased social benefits), while for the last two, in increased social costs. These components are then added together (in Section 8), and the possible divergence of social and private costs of energy and employment are considered.

Whether mandatory deposits pass or fail this social test depends critically on one's evaluation of (i) the average value of the time it takes consumers to return empty containers, and (ii) the average value of the "eyesore" benefit to Michiganders of dramatically reduced (i.e., by around three-fourths) beverage container litter. If the average time cost of returning each "empty" is as low as one cent, then the average "eyesore" benefit need only be above $\$ 0.65$ per year per Michigander for the switch to mandatory deposits to be an efficient change. On the other hand, if the average time cost is five cents per "empty," then the average annual "eyesore" benefit must exceed $\$ 12.48$ per capita if mandatory deposits are to represent an improvement over the status quo. People's estimates of these values can vary greatly, and for many, the estimates fall close to these critical thresholds. It is not clear that, from an efficiency viewpoint alone, a system of mandatory deposits is either better or worse than the status quo. The decisive factor, for most people, is how a mandatory deposit system satisfies goals other than efficiency.

\section{METHODS AND ASSUMPTIONS}

Social evaluation requires the summation of the present value of the time stream of net benefits (i.e., benefits minus costs) due to a shift from the present beverage delivery system to the system which would emerge under mandatory deposits. With mandatory deposits, three kinds of changes can be envisioned: (i) the total consumption of beer and soft drinks might change; (ii) there would be a shift in the mix of containers, from cans to bottles, from "one-ways" to refillables; and (iii) the average number of fillings per refillable bottle might change. In this section, the evidence about these is examined, and the assumptions underlying the remainder of the paper are made explicit.

If mandatory deposits nonmarginally affected the consumption rates of beer and soft drinks, we would need to consider the consumer willingness-to-pay and the producer costs of the increased or decreased beverage output. And as the container mix shifts away from cans and one-way bottles toward returnable, and returned, bottles, two things happen that can affect consumption: a loss of

solid waste came to just $\$ 176$ million, it would appear that the ban's annual sacrifice of $\$ 800$ million in tax revenues makes it an expensive way to purchase relatively small reductions in roadside litter and solid waste.

${ }^{2}$ For a contrary view, that benefit-cost analysis can and should consider goals other than efficiency, see Dasgupta et al. [5]. 
convenience and a reduction in average money price. The loss of convenience consists of time costs in returning bottles and of reduced choice among containcrs, sizes, and brands. (These not only are perceived by consumers as costs but indeed are real social costs of a mandatory deposit system, and they will be considered at length in Section 7). Unfortunately, the importance of this loss of convenience is inherently difficult to assess with confidence.

With money prices, we are on more solid ground. First of all, it is widely observed in fact that the price of beverages in refillable bottles (if they are returned) is lower than the price in one-ways (cans or bottles). This observed differential varies among times, places, and observers, but ranges as high as $35 \%{ }^{3}$ Unfortunately, this does not tell us much about the effect on prices of a switch from a system of largely one-ways to a system of largely refillables. It is often maintained that the current differential reflects price discrimination and that the low price of refillables would not continue in a largely refillables system [15, p. 307]. Better estimates of the impact of mandatory deposits on prices come from comparisons of Oregon and Vermont, either before and after the changes in their delivery systems or with other states. Such studies generally agree that prices remained unchanged or declined slightly as a result of the introduction of mandatory deposits. ${ }^{4}$

The evidence of Oregon and Vermont suggests that the impacts on convenience and money price are largely offsetting as far as the resulting consumption is concerned. The principal investigations of the Oregon law conclude that the sales volume either declined slightly [2, pp. II, 16-27 and 76-87] or cxpcricnecd "no change" $[10$, p. 15$] .{ }^{5}$

On balance, it is not unreasonable to assume that the consumption of beer and soft drinks changes very little as a result of the introduction of mandatory deposits; and accordingly, any benefits or costs due to an altered consumption of beverages in the short or long run can be ignored.

There is one other potential benefit or cost not directly related to the delivery of beverages that must be considered. The American changeover to one-way containers during the past 20 years has been accompaned by a dramatic increase in the size of plants in both the brewing and the soft drink (bottling) industries. There is the distinct possibility that a return to returnables would be accompanied by a return to more and smaller brewers and soft drink bottlers. If such a return meant higher real per-unit production costs, ${ }^{6}$ these would have to be considered as a social cost of the mandatory deposit measure. Of course, offsetting these higher costs, partly at least, would be reduced transport costs. Rather than speculate about these changes, I will assume that the present s:ze, structure, and geographical distribution of plants continues under mandatory deposits, and

\footnotetext{
${ }^{3}$ See, for example, E.P.A. [8, p. 29]; Hearings [15, pp. 170, 305, 354]; Task Force [34, p. 55]; Bingham and Mulligan [3, p. 53]; Hannon [11, p. 26]; and Maillie [23, p. 62].

${ }^{4}$ Pinsky [27, p. 3]; Hearings [15, pp. 819-823]; League of Women Voters [19, p. 3]; A.D.S. [2, pp. II, 35-36 and II, 97-99]; and Gudger and Bailes [10, p. 16]. The prices referred to are average prices. The price of beverages in cans and one-way bottles rises (see Appendix 1), but the proportion of such containers declines precipitously.

${ }^{5}$ Vermont evidence is less reliable because of its poorer data, fewer careful studies, and lesser competition.

${ }^{6}$ See Elzinga [7, pp. 233-236].
} 
hence that production costs of beverages are unaffected by the distribution system. ${ }^{7}$

What we ask then is whether the present value of the net benefits of switching (from the present beverage delivery system to that which would emerge under mandatory deposits) is positive, i.e., whether

$$
B=\sum_{t=0}^{\infty} \frac{B_{t}}{(1+i)^{t}} \gtrless 0,
$$

where $B$ is the present value of real net benefit, $B_{t}$ is the real net benefit in year $t$, and $i$ is the social discount rate. If $b$ is the real net benefit per beverage filling, and is independent of the number of fillings per year and is unchanging over time, then $B$ can also be written as

$$
B=b \sum_{t=0}^{\infty} \frac{f_{t}}{(1+i)^{t}},
$$

where $f_{t}$ is the number of fillings in year $t$. Since we are assuming that $f_{t}$ is the same under each of the two delivery systems, the entire term following the summation $s: g n$ is unaffected by the beverage delivery system, and hence $B \gtrless 0$ as $b \gtrless 0$. In this paper, we therefore seek the value of $b$, for Michigan and for $1974 ;^{8}$ the question then is whether $b$, the real net social benefit per filling, is greater or less than zero.

The assumption that $b$ is independent of $f$ and of $t$ is wrong, ${ }^{9}$ but to try to guess which elements of $b$ would rise or fall with $f$ and/or $t$, and by how much, is a nearly hopeless task. Here, then, we seek the values of the various components of $b$ for $f=3.95$ billion $^{10}$ and $t=0$ (i.e., 1974). The precise question we are in effect asking is a counterfactual historical exercise: would it have been preferable to have had a mandatory deposit system, which had been completely adjusted to, in Michigan in 1974 ?

Since a system of mandatory deposits seriously raises prices of beverages delivered in unrefillable, "one-way" containers relative to the prices in refillable bottles, consumer demand undoubtedly shifts away from cans and unrefillable bottles toward refillables. ${ }^{11}$ But a priori thinking tells us little about the extent of the shift. The Oregon evidence is clear-within a year or two of the mandatory deposit, more than $90 \%$ of all beer and soft drink containers were refillable. ${ }^{12}$ Since this was achieved with a $2-5$ cent per container deposit, whereas Michigan's will be 10 cents, I intend to assume that mandatory deposits will induce a $100 \%$ refillable bottle system. ${ }^{13}$ Since the actual percentage would be at least somewhat less, the resulting calculation of $b$ will overstate its true absolute value, though not by more than $10 \%$ if Michigan reaches Oregon's percentages. What is critical, however, is that this $100 \%$ refillable assumption does not affect the sign of $b$;

${ }^{7}$ Obviously, where there are changes in the container mix and there are production or distribution cost differentials between containers, these will be considered.

${ }^{8}$ The latest for which there are extensive data.

- At the very least, it neglects differential transition rates among the components of $b$.

10 The number of beer and soft drink fillings consumed in Michigan in 1974.

${ }^{11}$ See Appendix 1. Whether noncompetitive supplicrs would respond to the altered demand is a question raised by Jeigh and Warshaw [20].

${ }^{12}$ Gudger and Bailes [10, pp. 18-23]; A.D.S. [2, p. 1I, 3, 67]; and Waggoner [37, pp. 21-22].

${ }^{13}$ Compared to the actual 1974 Michigan figure of $27 \%$ refillables $[28$, p. 140$]$. 
hence the conclusion whether mandatory deposits are socially desirable is not influcneed at all.

Finally, there is need for an assumption about "trippage," i.e., the average number of beverage deliveries per refillable bottle, under a mandatory deposit system. ${ }^{14}$ While clear in principle, measuring trippage in an unevenly growing system is not easy, ${ }^{15}$ and estimates for the United States vary somewhat. The national average is about 14 for soft drinks and 20 for beer ; ${ }^{16}$ and for all Michigan beverages, the estimated trippage is 15 [28, p. 148].

The problem is knowing what happens to trippage under a mandatory deposit system. Much a priori thinking has argued that trippage would fall, principally because those who now buy returnables are an especially careful and frugal minority. ${ }^{17}$ The evidence, on the other hand, indicates that trippage rises as a result of mandatory deposits, either slightly ${ }^{18}$ or greatly. ${ }^{19}$ Since Oregon was typical of U.S. beverage consumption (before its mandatory deposits) with respect to the percentage of refillables used and the trippage of those refillables, the rise in trippage there becomes especially noteworthy. Explanations are tentative but rest largely on the greater ease of return (per container) once consumers bave adjusted to the new system [10, pp. 28-29]. On balance, then, it seems reasonable that trippage remains at 15 in Michigan after the introduction of mandatory deposits and the complete switch to refillable bottles.

In the next five sections, magnitudes are estimated of the five principal components of the net benefit $(b)$ of a complete switchover to refillable bottles under Michigan's mandatory deposit system. Three of these components are positivereduced litter, reduced solid waste, and reduced container costs-and two of the components are negative- - higher production and distribution costs and reduced consumer convenience. The five components are then brought together in Section 8 .

\section{LITTER}

The most common ingredient in popular concerns about mandatory depusits on beverage containers is litter. It appears on private property, city streets, parks, and highways, although the data on clean-up costs of only the last are widely collected. Litter consists heavily of beverage containers and their attendant tops and cartons, although how heavily is much disputed. Litter imposes two

${ }^{14}$ Trippage $(T)$ is related to the probability that a given bottle is returned in reusable condition $(r)$ as follows:

$$
T=(1-r)+2 r(1-r)+3 r^{2}(1-r)+\cdots,
$$

or, summing the series,

$$
T=1 /(1-r) .
$$

Thus, a return rate of $90 \%$ implies a trippage of 10 ; and a return rate of $95 \%$ implies a trippage of 20 .

${ }^{15}$ See [6, Appendix C].

${ }^{16}$ The source is the Glass Containers Manufacturers Institute (1970), cited in [3, p. 55n]. See also [11, p. 39].

${ }^{17}$ See, for example, Maillie [23, p. 10]. Gudger and Bailes [10, pp. 23-24] give further a priori arguments why trippage should decline. But not all have so argued; see, for example, Bingham and Mulligan [3, p. 54].

${ }^{18}[2$, pp. II, 37,102$]$ and $[15$, p. 146$]$

${ }^{19}[10$, pp. $24-27]$ and $[15$, pp. 168,821$]$ 
TABLE I

Estimated Composition of Michigan Beverage Container Litter, 1974

\begin{tabular}{|c|c|c|c|c|c|}
\hline \multirow[t]{3}{*}{ Type of container } & \multicolumn{3}{|c|}{ Number (millions) } & \multicolumn{2}{|c|}{ Litter rate $(\%)$} \\
\hline & \multirow[t]{2}{*}{ Fillings } & \multicolumn{2}{|c|}{ Littered } & \multirow[t]{2}{*}{ Rao } & \multirow[t]{2}{*}{ Porter } \\
\hline & & Rao & Porter & & \\
\hline Cans & 2150 & 317 & 140 & 14.74 & 6.51 \\
\hline Nonrefillable bottles & 730 & 61 & 21 & 8.36 & 2.88 \\
\hline Refillable bottles & 1070 & 43 & 7 & 4.02 & 0.65 \\
\hline Total & 3950 & 420 & 168 & 10.64 & 4.25 \\
\hline
\end{tabular}

Sources: [28, pp. 23, 141]; [3, p. 32].

costs on society: (i) the pickup cost, which is much higher than the cost of disposing of containers through the normal solid waste disposal channels; and (ii) the amenity cost of the stock of litter, which is essentially an "eyesore" cost but also involves medical, wildlife, and farm equipment costs. ${ }^{20}$

Of the 3950 million containers of beverages consumed by Michiganders in 1974, it is cstimated that between 168 million and 420 million containers ended up as litter along the state's roads. ${ }^{21}$ This means that $4-11 \%$ of beverage fillings result in a littered container (on roads alone). Different kinds of containers are not equally likely to be littered (see Table I) ; according to the two estimates there, refillable bottles are only $15-38 \%$ as likely to be littered as the average container. It seems clear that a significant reduction in beverage container litter can be expected from a switch to an all-refillable delivery system.

But how important is such container litter in the overall problem? This depends very much on what one considers to be the problem. From a viewpoint of injury, sharpness matters; for aesthetics, probably number and volume; for the costs of pickup, weight, volume, number, sharpness (among other characteristics) all matter. Actual litter counts are always done on either a volume or a number (i.e., piece-count) basis, usually the latter. And the importance of containers differs accordingly: 140 cigarette butts have the same volume as one 12-oz can. Although there is great variance in the data here too, one can say roughly that beverage containers make up about $60 \%$ of all litter by volume but only about $20 \%$ by piece-count.

As one might guess, the greatest variance of all is of the reduction in litter which can be atlributed, in Oregon and Vermont, to the mandatory deposit legislation. For Oregon, various sources report: there was "a $74 \%$ reduction in

${ }^{20}$ Litter is not the only form of pollution differently generated by refillables and one-ways, although it is quantitatively so much the most important that it is the only one considered here. Other relevant external diseconomies involve (with the consumption or generation by 15-trip refillable bottles as a percentage of that by aluminum cans given in parentheses): water usage $(87 \%)$, industrial solid waste $(21 \%)$, atmospheric emissions $(25 \%)$, and water-borne wastes $(52 \%)[16$, p. 21$]$. Energy consumption will be further discussed in Section 8.

${ }^{21}$ The high figure is from $\operatorname{Rao}[28$, p. 23]. The container litter per mile figures of Finkner [9] were raised slightly to allow for trend and then multiplied by the Michigan road mileage. The low estimate, mine, applies Finkner's estimates of percentage of fillings littered (not raised for trend) to the number of Michigan fillings. 
TABLE II

Litter Reduction in Oregon

\begin{tabular}{lcc}
\hline Source & \multicolumn{2}{c}{ Percentage reduction in } \\
\cline { 2 - 3 } & $\begin{array}{c}\text { Beverage container } \\
\text { litter }\end{array}$ & Total litter \\
\hline Gudger and Bailes $[10]$ & 92 & 30 \\
A.D.S. [2] & 66 & 10 \\
\hline
\end{tabular}

Source: [34, p. G-8]

littered beverage containers" ; "overall litter reduction turned out to be 10.6 percent in the first year. . . By September of $1974 \ldots$ total litter had increased six percent"; ${ }^{23}$ "reductions of from 75 to $85 \%$ "; "the number of beverage containers roadside litter (sic) decreased by 81 percent.... Total litter was down 63 percent" ; ${ }^{25}$ "cut roadside litter by one-tenth" ; ${ }^{26}$ and "littering of beverage containers increased $127 \%$ ". ${ }^{27}$ The two most widely quoted and careful studies of the Oregon experience show only somewhat greater agreement on the impact on litter, as Table II shows. For Vermont, there seems to be general agreement that container litter dropped $76.1 \%,{ }^{28}$ but few numbers concerning the effect on total litter.

From all this conflicting testimony, I propose the following. Since trippage of refillables is not expected to decline when mandatory deposits are instituted, neither should we expect any dramatic change in the proportions in which the discarded refillable bottles are littered or placed in solid waste disposal. This represents a compromise between the argument that "innate" litterers, who do not now buy refillables, will continue to litter at higher rates and the argument that education, convenience, and/or sclf-interest will reduce litter rates of refillables even below present levels. Thus, I expect a decline in beverage-container litter, with complete conversion to refillable bottles, of from 62 to $85 \%{ }^{29}$

This means that there would have been 142-261 million fewer littered beverage containers to pick up in $1974 .{ }^{30}$ This represents a real saving of resources. The extent of this saving depends upon the cost of picking up container litter. Estimates usually run from as low as one cent per container (picked up and disposed of) $[28$, p. 26] to as high as four cents per container [3, p. 34], although the cost is said to be 30 cents per container in New York City [38, p. 46]. Applying the one and four cent figures to the litter estimates and dividing by the total Michigan beverage fillings yields a litter pickup enst per filling of between 0.04 and $0.26 \mathrm{c/f}$

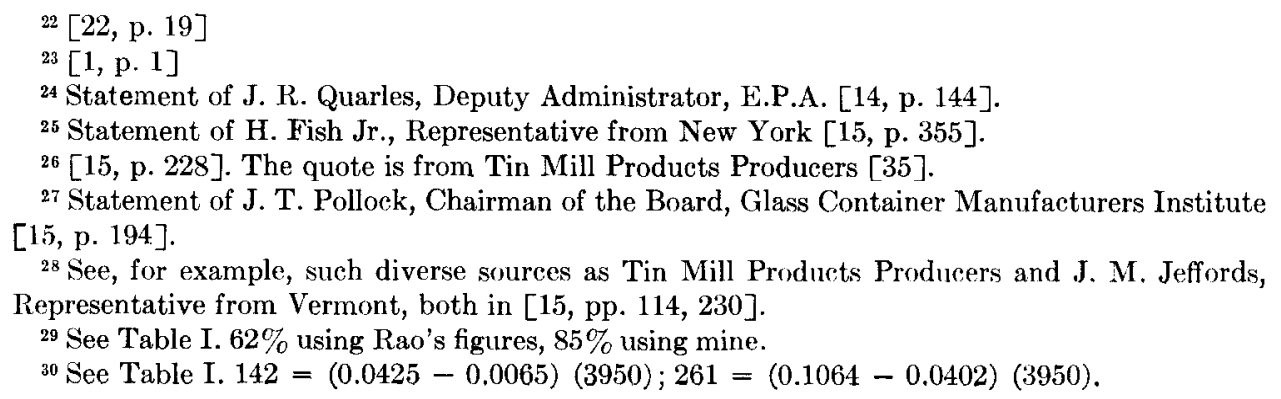


(where $\phi / f$ means cents per filling). This range compares closely, after allowance for 1969-1974 inflation, with the Research Triangle Institute studies. ${ }^{31}$

These figures are not large. ${ }^{32}$ Even the upper end of the range says that, if beverage consumers were somehow to be charged for the cost of picking up all beverage container litter, the price of each beverage filling would rise by barely one quarter of one cent.

The main cost of litter is incurred not when it is picked up but while it lies there. What happens to the average stock of litter when the rate of littering drops between 62 and $85 \%$ depends upon the frequency with which it is picked up. One can easily make arguments that Michigan will/should pick up its roadside litter more/less frequently once the litter rate falls so drastically. ${ }^{33}$ Obviously, if pickups are made more frequently, the average stock of beverage container litter will fall by more than $62-85 \%$; and vice versa. ${ }^{34} \mathrm{I}$ wish to avoid this related but tangential policy issue by assuming that the frequency of litter pickup is unchanged, and hence that the average stock of beverage container litter also declines by $62-85 \% .^{35}$

What is a $62-85 \%$ reduction in the average stockpile of Michigan's roadside (and presumably other) beverage container litter worth to Michiganders? Quantification of this benefit is difficult, and there really are no hard data to use. One might creep up on an estimate by enumerating the specific damages caused by the litter stock and assuming that a given percentage reduction in that stock would bring about the same percentage reduction in those damages. Two examples:

1. Personal injury. It is reported that 300,000 "litter injuries" occur in California per year. ${ }^{36}$ If the same rate holds in Michigan and the cost in inconvenience, pain, and medical care is arbitrarily put at $\$ 30$ per injury, then a $62-85 \%$ reduction in litter would be worth $\$ 0.27-\$ 0.37$ per Michigander per year in experted averted injury damage. ${ }^{37}$

2. Farm equipment damage. I can find no studies of this oft-mentioned cost due to litter finding its way into farm fields to the detriment of machinery. But an order of magnitude is readily visualized. If each farm family suffers (say) \$50

${ }^{31}$ Which come to around $0.12 \phi / f$ for the United States. The only other study I have found [6] implies a $0.03-0.04 \phi / f$ pickup cost (p. 53).

${ }^{32}$ Because the figures are small, I shall use only the midpoint of the range (i.e., $0.15 \phi / f$ ) in Section 8.

${ }^{33} \mathrm{~A}$ formal model is developed in Appendix 2 to derive the optimal frequency of pickup. It is possible that the optimal frequency increases, decreases, or even is unchanged.

${ }^{34}$ All this assumes that all litter is collected during the periodic pickup. But if a constant fraction is collected at given intervals, a $z \%$ reduction in the rate of litter (at time $t$ ) will still lead to a $z \%$ reduction in the average stock of litter accumulated (since time $t$ ).

${ }^{35}$ The frequency and social costs of private litter pickup-i.e., of formal and informal seavenging-is also assumed to remain constant. Such effort is subject to two forces, greater average revenue per container scavenged and fewer containers per land area, which tend to offset each other. In any case, litter is a "commons" and as such may be overscavenged-an inefficiency we ignore. On the rate of return to scavenging, see $[6, \mathrm{pp} .50 \mathrm{ff}]$.

${ }^{36}$ According to a 1975 study cited in [32, p. 69].

${ }^{37}$ Since Michigan's population is only $45 \%$ of California's, the injury rate would be 134,000 per year, or $1.47 \%$ of its population. $(\$ 30)(0.0147)(0.62$ or 0.85$)=\$ 0.27$ or $\$ 0.37$. On a cents-perfilling basis, the averted damage is $0.06-0,09 k / f$. 


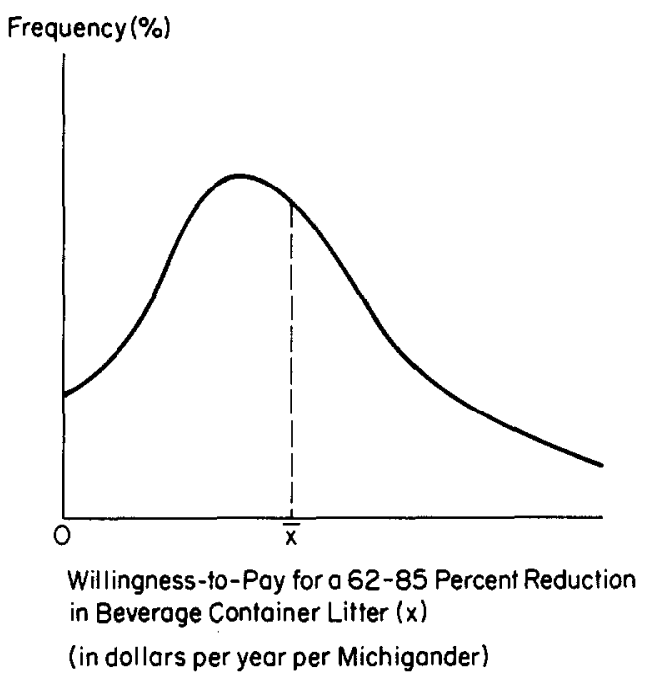

Frg. 1. Willingness to pay for litter reduction.

per year of such damage, then a $62-85 \%$ reduction would be worth $\$ 0.26-\$ 0.36$ per Michigander per year. ${ }^{38}$

Neither of these is very large; but neither begins to capture the principal damage caused by litter-its amenity, or "eyesore," cost. Different Michiganders would pay different amounts per year for the privilege of being accosted, on average, by $62-85 \%$ less beverage container litter. Figure 1 shows the (hypothetical) frequencies, or percentages, of Michiganders at each possible willingnessto-pay per year ( $x$, measured in dollars per year per Michigander) for this litter reduction. ${ }^{39}$ Some, presumably, would pay nothing. ${ }^{40}$ The frequencies probably rise, as more are willing to pay a few cents per year, or even a few dollars. Eventually, the frequencies must fall, although not to zero until the last environmentalistmillionaire is counted. Our concern is with the mean willingness-to-pay $(\bar{x})$. Converted to cents per filling, the social benefit of such a litter reduction is $0.23 \bar{x} \phi / f$. Despite the fact that $\bar{x}$ is unknown, we can find critical ranges for it; this we will do, in Section 8, after the other costs and benefits have been considered.

The net benefit of mandatory deposits from the viewpoint of litter-first of enduring it and then of picking it up-is $(0.23 \vec{x}+0.15) \& / f{ }^{41}$

\section{SOLID WASTE}

Michigan generated 5.76 million tons of municipal solid waste in 1974, about $6 \%$ of which was beverage containers $[28$, p. 419$]$. This is the most important fact about the impact of mandatory deposits on solid waste: only a tiny part of

${ }^{38}$ Assuming fanilies of four; $3.4 \%$ of Michigan's population are in farm families (\$50) (1) $(0.034)$ $(0.62$ or 0.85$)=\$ 0.26$ or $\$ 0.36$. This is $0.06-0.08 \% / f$.

39 If nonmarginality can be ignored, this is also what Michiganders would have to be bribed to freely accept current litter levels rather than a $62-85 \%$ lower level. The fact that litter reduction is a public good makes it difficult to actually collect any part of this willingness-to-pay, but that is not the issue here.

40 I assume no one likes litter.

${ }^{41}$ Note that the costs of personal and equipment damage are not explicitly counted and hence are implicitly ineluded in the $\bar{x}$. Alternatingly, one could keep $\bar{x}$ as a pure eyesore figure and add something like $0.12-0.17$ to the 0.15 . 
especially concern for income distribution and employment. All of these are important considerations, but they should be complementary to, and not included in, an efficiency-oriented social benefit-cost analysis. ${ }^{2}$

The analysis here is an appraisal of Michigan's "bottle law" from the viewpoint of the welfare of Michiganders. Considered in detail (in Sections 3-7) are the five principal sources of changes in social benefits and costs: (i) litter (both pickup and "eyesore" costs); (ii) solid waste; (iii) containers; (iv) production and distribution; and (v) consumer convenience. For the first three, mandatory deposits result in reduced social costs (or increased social benefits), while for the last two, in increased social costs. These components are then added together (in Section 8), and the possible divergence of social and private costs of energy and employment are considered.

Whether mandatory deposits pass or fail this social test depends critically on one's evaluation of (i) the average value of the time it takes consumers to return empty containers, and (ii) the average value of the "eyesore" benefit to Michiganders of dramatically reduced (i.e., by around three-fourths) beverage container litter. If the average time cost of returning each "empty" is as low as one cent, then the average "eyesore" benefit need only be above $\$ 0.65$ per year per Michigander for the switch to mandatory deposits to be an efficient change. On the other hand, if the average time cost is five cents per "empty," then the average annual "eyesore" benefit must exceed $\$ 12.48$ per capita if mandatory deposits are to represent an improvement over the status quo. People's estimates of these values can vary greatly, and for many, the estimates fall close to these critical thresholds. It is not clear that, from an efficiency viewpoint alone, a system of mandatory deposits is either better or worse than the status quo. The decisive factor, for most people, is how a mandatory deposit system satisfies goals other than efficiency.

\section{METHODS AND ASSUMPTIONS}

Social evaluation requires the summation of the present value of the time stream of net benefits (i.e., benefits minus costs) due to a shift from the present beverage delivery system to the system which would emerge under mandatory deposits. With mandatory deposits, three kinds of changes can be envisioned: (i) the total consumption of beer and soft drinks might change; (ii) there would be a shift in the mix of containers, from cans to bottles, from "one-ways" to refillables; and (iii) the average number of fillings per refillable bottle might change. In this section, the evidence about these is examined, and the assumptions underlying the remainder of the paper are made explicit.

If mandatory deposits nonmarginally affected the consumption rates of beer and soft drinks, we would need to consider the consumer willingness-to-pay and the producer costs of the increased or decreased beverage output. And as the container mix shifts away from cans and one-way bottles toward returnable, and returned, bottles, two things happen that can affect consumption: a loss of

solid waste came to just $\$ 176$ million, it would appear that the ban's annual sacrifice of $\$ 800$ million in tax revenues makes it an expensive way to purchase relatively small reductions in roadside litter and solid waste.

${ }^{2}$ For a contrary view, that benefit-cost analysis can and should consider goals other than efficiency, see Dasgupta et al. [5]. 
TABLE IV

Estimates of Container-Cost Savings Due to Mandatory Deposits in Michigan, 1974

\begin{tabular}{|c|c|c|c|c|c|c|}
\hline \multirow[t]{2}{*}{ Type of eontainer } & \multicolumn{3}{|c|}{ Beer } & \multicolumn{3}{|c|}{ Soft drinks } \\
\hline & $\begin{array}{c}\text { Container } \\
\text { cost } \\
\text { (cents) }\end{array}$ & $\begin{array}{l}\text { Container } \\
\text { size } \\
\text { (ounces) }\end{array}$ & $\begin{array}{c}\text { Percentage } \\
\text { of sales }\end{array}$ & $\begin{array}{l}\text { Container } \\
\text { cost } \\
\text { (cents) }\end{array}$ & $\begin{array}{l}\text { Container } \\
\text { size } \\
\text { (ounces) }\end{array}$ & $\begin{array}{c}\text { Percentage } \\
\text { of sales }\end{array}$ \\
\hline Can & 4.6 & 12 & 69 & 4.7 & 12 & 40 \\
\hline Nonrefillable bottle & 4.4 & 12 & 17 & 6.3 & 16 & 20 \\
\hline Refillable bottle & 9.0 & 12 & 14 & 9.4 & 16 & 40 \\
\hline \multicolumn{7}{|c|}{ Average Cost per Filling } \\
\hline \multicolumn{2}{|c|}{$\begin{array}{l}\text { A. Actual } \\
\text { B. With mandatory deposits } \\
\text { C. Saving }\end{array}$} & $\begin{array}{l}4.01 \dot{\phi} / \mathfrak{f} \\
0.60 \dot{\phi} / \mathrm{f} \\
3.41 \dot{\mathrm{f}}\end{array}$ & & & $\begin{array}{l}3.38 \phi / \mathrm{f} \\
0.63 \dot{\phi}^{+} \mathrm{f} \\
2.75 \phi / \mathrm{f}\end{array}$ & \\
\hline
\end{tabular}

Source: [28, p. 149].

the reduction would be $2.1 \%{ }^{48}$ Accepting that percentage means that Michigan solid waste would have been 121 thousand tons less in 1974 with an all-refillable system.

Costs for collection and disposal of municipal solid waste have been variously estimated at $\$ 6$ to $\$ 36$ per ton [26, p. 18]. For Michigan in 1974, the cost was roughly $\$ 22$ per ton [28, p. 18]. Two further assumptions about solid waste disposal are helpful: (i) average and marginal costs are identical in the long run; and (ii) the cost per ton is the same for beverage containers as for other kinds of trash. Then multiplication indicates a net gain, through a complete conversion to refillables, of $\$ 2.66$ million for Michigan in 1974. This is the equivalent of $0.07 \phi / f$.

Practically nothing. And even if the entire beverage-container content of solid waste were to disappear, the saving would only be $0.19 \notin / f .{ }^{49}$ Nor do other estimates of the solid waste cost of the present largely disposable beverage delivery system differ much. ${ }^{50}$ In short, the current solid waste system disposes of beverage containers at a very small cost per filling.

The net benefit of mandatory deposits from the viewpoint of solid waste is $0.07 \notin / f$.

\section{CONTAINERS}

While refillable bottles initially cost about twice as much as one-way containers, ${ }^{51}$ the average refillable bottle is reused many times. This means that the cost of containers per filling would decline significantly if only refillable bottles were used.

Measurement of this saving is straightforward. Rao has collected from Michigan

${ }^{48}[6$, pp. 57-65]. They conclude $1.5 \%$, but they assume trippage of 9-12. Adjusting their data to trippage of 15 yields an estimate of $2.1 \%$.

${ }^{49}$ I.e., (6\%) (5.76 million tons) $(100 \notin / \$)(\$ 22 /$ ton $) \div(3950$ million fillings).

${ }^{50}$ For example, for the United States for 1969, Bingham and Mulligan [3, pp. 20-24, 122] estimated $0.11 \mathrm{~d} / \mathrm{f}$ (i.e., $\$ 93.3$ million to dispose of the containers associated with 82.7 billion fillings).

s1 Almost exactly twice as much in recent years. See Hannon $[11$, p. 11] and [15, p. 198]. 
glass and can manufacturers the initial container cost (in 1974) of the most commonly used sizes. These are shown in Table IV (with the container size and its percentage of sales). One can then compare the container cost per filling on our two assumptions: (i) that the trippage of refillable bottles remains at 15 under mandatory deposits, and (ii) that the mandatory deposit system induces a complete switch to refillables. The calculations are carried out in Table IV. Under the current composition of containers, the weighted-average cost per filling of the 1974 Michigan container was $4.01 \mathrm{k} / \mathrm{f}$ for beer and $3.38 \mathrm{k} / \mathrm{f}$ for soft drinks. A complete switch to refillable bottles averaging 15 trips would reduce these costs by $3.41 \notin / f$ for beer and $2.75 \phi / f$ for soft drinks. Weighting these two figures by their proportion of total beverage consumption, ${ }^{52}$ the saving in container cost emerges as $3.08 \phi / f .^{53}$

This $3.08 / f$ estimate is the saving in private container cost to brewers and soft drink bottlers. It is also the saving in social container cost only on the assumption that the price of containers equals their marginal social cost. There are two reasons for questioning this equality. One, if the raw materials involved are incorrectly priced, in the sense that their social opportunity cost exceeds their current market value, then the price of the containers would be below social cost. Since the raw materials involved-principally glass and aluminum-are plentiful, there seems little reason to worry on this score. ${ }^{54}$ And, two, if either the can or bottle industry marks up oligopolistically, the price of those containers would exceed their marginal cost. This issue is ignored here, although complexity is not the only justification; since so few of Michigan's beverage containers are made in Michigan, the price of those containers really does reflect their social cost to Michigan. ${ }^{55}$

The net benefits of mandatory deposits from the viewpoint of container cost is $3.08 \mathrm{k} / \mathrm{f}$.

\section{PRODUCTION AND DISTRIBUTION}

That refillable containers cost more than one-ways for filling and distribution is well known. At the filling stage, bottle lines run more slowly than can lines. Refillable bottles are heavier, which makes them more costly to load and transport. Their return for reuse requires additional storage, handling, and washing. And finally, the total stock of containers required to maintain a given flow of fillings (i.e., the "float") is increased when a complete system of returnable bottles is achieved.

This very listing of the many sources of production and distribution differentials gives an idea of the problems associated with estimation. It is nccessary to add up many figures, no one of which can be estimated too confidently. Moreover, since the resulting total is not insignificant, the components have been

${ }^{52}$ For beer, 1.95 billion fillings, and for soft drinks, 2.00 billion fillings [28, p. 149$]$.

${ }_{53}$ The comparable figure for Oregon has never been calculated, but it can be derived from data presented in Gudger and Bailes [10, pp. 38-40, 49-51]. The container cost saving is $2.86 \phi / f$ for beer and $2.02 \phi / f$ for soft drinks, or a weighted average saving of $2.48 \phi / f$. The lower estimates are largely attributable to the fact that in Oregon refillable bottles were already more extensively used before the law than in Michigan-for beer, $32 \%$ versus $14 \%$; and for soft drinks, $60 \%$ versus $40 \%$.

${ }^{54}$ Energy use is another matter, and we will consider it in Section 8.

${ }^{55}$ This reasoning also justifies our ignoring any pollution externalities in container-making. 
frequently and conflictingly studied by interested parties to the mandatory deposits controversy. Rather than attempt to footnote and compare all these variations, I will derive my estimates from just one study, which was done for Michigan and which drew on a wide selection of Oregon, E.P.A., and industry sources [28, pp. 152-178]. There is, however, no reason for thinking that the possibly large errors in each of the component estimates will disappear in the summation, and a procedure for handling this uncertainty will be discussed at the end of this section.

Compounding the problems are the great variety of production and distribution channels through which beer and soft drinks are delivered in Michigan. But there are essentially three groups whose costs would be affected by a switch to refillables: (1) retailers; (2) soft drink bottlers; and (3) brewers. We examine each in turn.

1. Retailers. About $64 \%$ of the soft drinks and $91 \%$ of the beer are sold through grocery stores [28, p. 153], and their share of the sales in nonrefillable containers is undoubtedly higher. Little error is therefore introduced by concentrating on the increased costs of grocery stores and attributing these same costs to other retailers. There are three principal additions to social cost here, and we estimate each below, initially in cents per additional returned bottle ( $\phi / a r b)$.

(i) Labor. All the various retail-level operations of processing one returned bottle take about $12 \mathrm{sec}$. At an average wage of $\$ 3$ per hour, this represents 1.00 c/arb [28, p. 154]. ${ }^{56}$

(ii) Storage. $0.10 \phi / \operatorname{arb}[28$, pp. $155-156] .{ }^{57}$

(iii) Investment. Changeover investments will total $\$ 1.81$ million for Michigan grocers [28, p. 156]. Allowing a $10 \%$ depreciation rate and a $10 \%$ interest rate, this can be annualized to $\$ 0.36$ million. Since there would be 2.69 billion additional returned bottles, ${ }^{58}$ this represents $0.01 k /$ arb.

The total of the three costs is $1.11 \mathrm{k} / \mathrm{arb}$. Converting this to cents per filling to make it comparable to the other benefit and cost components yields a net cost to retailers of $0.76 \notin / f .{ }^{59}$

2. Soft drink bottlers. The data refer to in-state bottlers, whose costs are assumed to be Michigan social costs. It is necessary to assume that out-of-state bottlers experience similar cost increases and that these increases are exactly passed on to Michigan consumers (so that their private cost increases indeed become social cost increases for Michiganders). There are five affected cost categories.

(i) Filling lines. Cans of soft drinks are filled about four times as fast, in terms of man-hours per filling, as bottles. Thus, the complete switch to refillable bottles will raise these costs by $0.33 \phi / f$ for each former can-full [28, p. 174]. Since $40 \%$ of the soft-drink fillings are now in cans, the increased cost per filling of all soft drinks would be $0.14 \phi / f$.

(ii) Float. An all-refillable system requires 0.24 billion new bottles [28, p.

${ }^{56}$ Compare this to $0.83-0.85 \Leftrightarrow / \operatorname{arb}[34$, p. G-G-14] and 1.00-1.61 $\Leftrightarrow /$ arb $[13$, p. 530$]$. I assume, for now, the equality of wage and social opportunity cost. The question whether this is, especially here, appropriate will be raised in Section 8.

${ }^{67}$ This is a compromise between Oregon experience $(0.06 \phi /$ arb $)$ and grocers' claims $(0.17-0.82$ $\phi / \operatorname{arb}[15$, p. 162]).

${ }^{58}$ I.e., 2.88 billion beer and soft drink fillings per year, now in one-ways (of the total 3.95 billion fillings) would be delivered in refillable bottles, of which $14 / 15$ would be returned.

${ }^{59}$ I.e., (1.11 $\left.\mathrm{k} / \mathrm{arb}\right)(2.69$ billion arb) $\div$ (3.95 billion $f)$. 
especially concern for income distribution and employment. All of these are important considerations, but they should be complementary to, and not included in, an efficiency-oriented social benefit-cost analysis. ${ }^{2}$

The analysis here is an appraisal of Michigan's "bottle law" from the viewpoint of the welfare of Michiganders. Considered in detail (in Sections 3-7) are the five principal sources of changes in social benefits and costs: (i) litter (both pickup and "eyesore" costs); (ii) solid waste; (iii) containers; (iv) production and distribution; and (v) consumer convenience. For the first three, mandatory deposits result in reduced social costs (or increased social benefits), while for the last two, in increased social costs. These components are then added together (in Section 8), and the possible divergence of social and private costs of energy and employment are considered.

Whether mandatory deposits pass or fail this social test depends critically on one's evaluation of (i) the average value of the time it takes consumers to return empty containers, and (ii) the average value of the "eyesore" benefit to Michiganders of dramatically reduced (i.e., by around three-fourths) beverage container litter. If the average time cost of returning each "empty" is as low as one cent, then the average "eyesore" benefit need only be above $\$ 0.65$ per year per Michigander for the switch to mandatory deposits to be an efficient change. On the other hand, if the average time cost is five cents per "empty," then the average annual "eyesore" benefit must exceed $\$ 12.48$ per capita if mandatory deposits are to represent an improvement over the status quo. People's estimates of these values can vary greatly, and for many, the estimates fall close to these critical thresholds. It is not clear that, from an efficiency viewpoint alone, a system of mandatory deposits is either better or worse than the status quo. The decisive factor, for most people, is how a mandatory deposit system satisfies goals other than efficiency.

\section{METHODS AND ASSUMPTIONS}

Social evaluation requires the summation of the present value of the time stream of net benefits (i.e., benefits minus costs) due to a shift from the present beverage delivery system to the system which would emerge under mandatory deposits. With mandatory deposits, three kinds of changes can be envisioned: (i) the total consumption of beer and soft drinks might change; (ii) there would be a shift in the mix of containers, from cans to bottles, from "one-ways" to refillables; and (iii) the average number of fillings per refillable bottle might change. In this section, the evidence about these is examined, and the assumptions underlying the remainder of the paper are made explicit.

If mandatory deposits nonmarginally affected the consumption rates of beer and soft drinks, we would need to consider the consumer willingness-to-pay and the producer costs of the increased or decreased beverage output. And as the container mix shifts away from cans and one-way bottles toward returnable, and returned, bottles, two things happen that can affect consumption: a loss of

solid waste came to just $\$ 176$ million, it would appear that the ban's annual sacrifice of $\$ 800$ million in tax revenues makes it an expensive way to purchase relatively small reductions in roadside litter and solid waste.

${ }^{2}$ For a contrary view, that benefit-cost analysis can and should consider goals other than efficiency, see Dasgupta et al. [5]. 
(vi) Return shipping. These costs, which includo washing, amount to 1.36 cents per returnable bottle, or $1.09 \& / f .{ }^{71}$

The total of these six additional costs is $2.71 \mathrm{k} / \mathrm{f}$.

These production and distribution cost increases can now be added with attention to the weights, as follows:

$$
(0.76)+(1.32)\left(\frac{2.00}{3.95}\right)+(2.71)\left(\frac{1.95}{3.95}\right)=2.77 \phi / f
$$

This represents a net cost of mandatory deposits. It should be noticed in passing that the increase in production and distribution costs is less than the decrease in container costs $(3.08 \phi / f$; see Section 5$)$. This difference is what makes it probable that the money price of beverages will decline in an all-refillable delivery system. The time price-i.e., of returning "empties"-of course rises (see Section 7 ). While the net effect of these two forces for the average consumer is unclear, there is no necessary inconsistency between the data of Sections 5 and 6 and our assumption in Section 2 that total consumption is unaffected by the choice of delivery system.

It should also be noted that the additional production and distribution cost is much higher for beer than for soft drinks: $3.47 \phi / f$ versus $2.08 \phi / f$. This is largely attributable to the fact that returnables already comprise a much larger share of soft drink sales than of beer sales. ${ }^{72}$ But even if one changes these additional cost estimates from a per-filling basis to a per-newly-returnable-bottle basis, there is still a sizeable gap. ${ }^{73}$ It suggests to me that these figures are highly uncertain; since they are so large and hence so critical to the overall social assessment, we will consider (in Section 8) two alternative estimates - one $25 \%$ above $2.77 \& / f$ and one $25 \%$ below $2.77 \notin / f .{ }^{74}$

\section{CONSUMER CONVENIENCE}

Here, more than anywhere else except for the social valuation of the reduced stockpile of beverage container litter ( $\bar{x}$ of Section 3 ), we move into the realm of conjecture. Gone are the conflicting numbers of industrialists and environmentalists. Clearly, there are social costs of switching to an all-refillable (and 14/15 refilled) bottle system that can be discussed under a single rubric, loss of consumer convenience. After all, people switched to one-ways over the past 20 years, despite continued price differentials in favor of refillable bottles - these people have demonstrated that easy disposal of containers is worth something to them. The question is how much.

First, it is necessary to pinpoint more exactly where the source of that gain in convenience is-or more precisely, the source of the loss of convenience that would accompany a return to a system of refillables. Chief among these is clearly the expense of time-and possibly "bother" 75 -incurred in returning the empty

${ }^{71}[28$, p. 162$] 1.09=(1.36)(1.68)(14 / 15) \div(1.95)$.

$7240 \%$ versus $14 \%$.

${ }^{73} 4.03 \phi / \mathrm{nrb}$ versus $3.46 \% / \mathrm{nrb}$, where nrb means newly returnable bottle.

${ }^{74}$ Even this lower figure $(2.08 \phi / f)$ is higher than most previous estimates-see, for example, Kopcke [18, pp. 6-7] and Gudger and Bailes [10, Chap. 3].

${ }^{75}$ See Scitovsky [30], passim, but especially Chap. 8. 


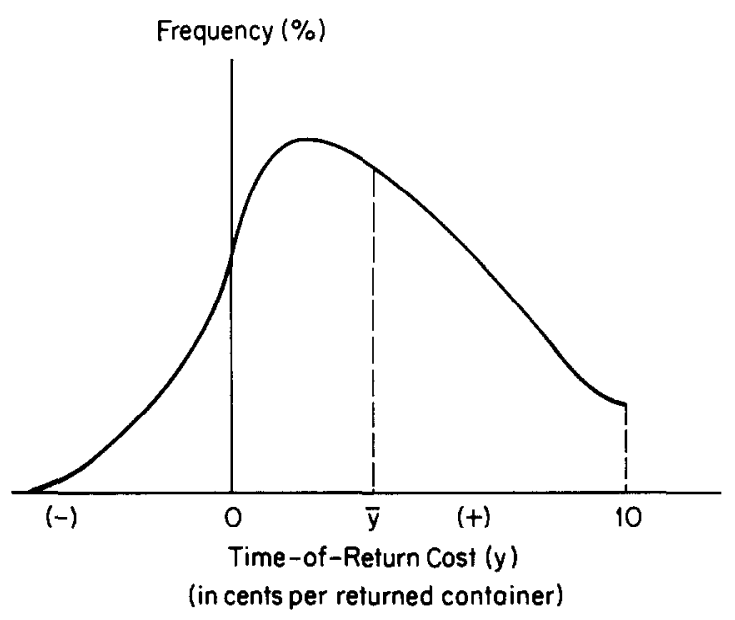

Frg. 2. Cost of returning containers.

bottles. The other sources of consumer loss are by comparison, I think, sufficiently minor that they should be listed and then ignored:

(1) The loss of options. It is often claimed that under mandatory deposits the variety of containers, sizes, and brands available to consumers will be reduced. Certainly the availability of cans is reduced, and some people distinctly prefer to drink beverages from cans. And the number of sizes and shapes diminishos, espocially where certain containers are "certified" for lower deposit rates. ${ }^{76}$ The evidence is unclear about brand choice. In Oregon, the share of the 11 largest selling beers increased from $95.7 \%$ in 1971 to $98.5 \%$ in $1972 .{ }^{77}$ But in Vermont, 15 new brands were introduced after the passage of the law $[31$, p. 2$]$. Tending to offset these are the increased options available to consumers in that more-indeed, all-stores redeem deposits on returned containers.

(2) Storage costs. For some people the need to collect "empties" could crowd their living space or impose sanitary costs.

(3) Financial return costs. For some shoppers, the return of containers could mean higher cost in money as well as in time.

The real social cost, I assume, lies not in these but in the time, effort, and/or bother incurred by the necessity to keep, organize, and transport empty containers and then to check them in during a shopping trip. What we need, conceptually, is knowledge of the willingness-to-pay-to-avoid-this-inconvenience of each person who returns a container for deposit, for this is that person's time-ofreturn cost. ${ }^{78} \mathrm{~A}$ hypothetical frequency (i.e., percentage) distribution of these time-of-return costs $(y)$ is shown in Fig. 2 (in cents per returned container).

For some pcople, $y$ is negative. For them, the psychic benefits of sparing the environment, saving energy, or husbanding resources outweigh any inconvenience. Some of these people already use refillable bottles, and they are of course excluded

${ }^{76}$ A.D.S. [2, pp. II, $\left.88 \mathrm{ff}.\right]$.

${ }^{77}[2$, p. II, 94] (It is curious that so large a change occurred in 1972 when the mandatory deposits functioned only for the final quarter of that year.) Consumers, however, did not perceive any reduction of brand choice [2, pp. III, 30-32].

${ }^{78}$ Excluding those people who already return refillables under the existing system. Here again, the difference between the equivalent and compensating variations is ignored. 
TABLE $\mathrm{V}$

The Social Benefits and Costs of a Change to Mandatory Deposits in Michigan, 1974

\begin{tabular}{|c|c|}
\hline Item (section) & Benefit $(+)$ or cost $(-)$ \\
\hline Litter (3) & $+0.15+0.23 \bar{x}$ \\
\hline Solid waste (4) & +0.07 \\
\hline Containers (5) & +3.08 \\
\hline Production and distribution $(6)$ & -2.77 \\
\hline Consumer convenience ( 7 ) & $-0.68 \bar{y}$ \\
\hline Net & $+0.53+0.23 \bar{x}-0.68 \bar{y}$ \\
\hline
\end{tabular}

from the distribution in Fig. 2. But there are others who would use refillable bottles if they were more readily purchasable and returnable--the number of one-way containers delivered, with no financial reward, to recycling stations attests to the existence and importance of this group.

There are others-probably a majority-for whom $y$ is positive but small (i.e., a few cents). The demographic profile of those who do the returning indicates that this is a sizeable group: the housewife, the unemployed, the retired, the disabled, and the young. ${ }^{74}$

The distribution is truncated at $y=10$ cents per returned container because no one who values the convenience more highly would ever actually return a bottle. ${ }^{80}$ To some extent, their bottles become the $1 / 15$ that disappear into litter and solid waste; to some extent, their bottles are passed on to others whose value of $y$ is below 10-it is of course this latter person who actually incurs the inconvenience cost and hence is included in the frequency distribution of Fig. 2.

The mean $(\bar{y})$ is shown in Fig. 2. It is almost certainly positive; it is certainly less than 10. Few have dared to say more. Branch [4] reasoned: "If we assume that it takes five extra minutes to gather, load and return two cartons of six containers (this is probably low) and if we apply the minimum wage to this five minutes, we see that customers would use about a cent's worth of time for each returnable." Despite the fact that $\bar{y}$ is unknown, we can find critical ranges for it; this we will do, in the next section.

To put this inconvenience cost on a per-filling basis, we must recognize that $\bar{y}$ only applies to the bottles which are returned under mandatory deposits and which were not previously returned. Making this adjustment yields a net cost of mandatory deposits from the viewpoint of consumer inconvenience of $0.68 \bar{y}$ cents per filling. ${ }^{81}$

\section{THE SOCIAL BENEFIT-COST EVALUATION}

The various components of the social benefits and costs of a mandatory deposit system have been examined over the course of Sections 3-8. They are now added together, in Table $\mathrm{V}$, where an increased benefit (or reduced cost) due to manda-

79 One Coors survey showed that half of their can returners were school children under 16 [13, p. 556]. Altogether, the above groups comprised $71 \%$ of the can returners in the sample.

${ }^{80}$ Recall, the Michigan deposit is $10 \%$. For an interesting discussion of the optimal (i.e., from the viewpoint of the bottler) rate of deposit, see Massell and Parish [24].

${ }^{81}$ I.e., $0.68=(14 / 15)(2.88$ billion fillings now sold in one-ways $) \div(3.95$ billion $\mathrm{f})$. 


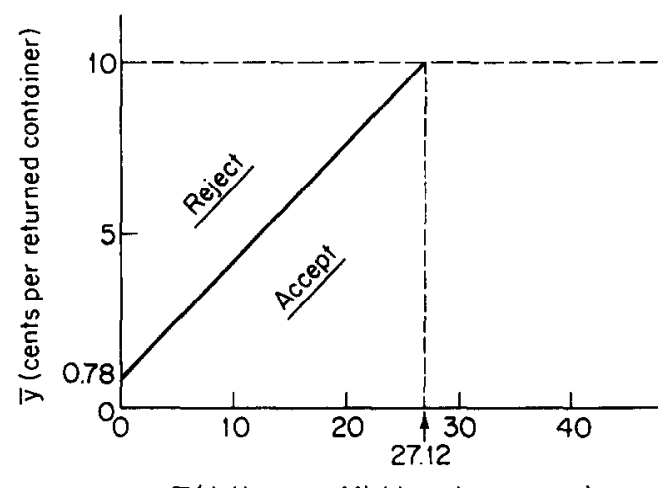

$\bar{x}$ (dol lars per Michigander per year)

FIG. 3. Critical locus for mandatory deposits.

tory deposits is entered with a positive sign; and a reduced benefit (or increased cost) with a negative sign. Notice that the total does not depend importantly on the cost of picking up litter $(+0.15)$ or the solid waste savings $(+0.07)$. Furthermore, the container cost saving $(+3.08)$ is estimated with accuracy, provided that the trippage assumption (15) is correct. Thus, the critical uncertainties in the overall evaluation lie in the two unknowns $(\bar{x}$ and $\bar{y})$ and in the possibly serious error in the production and distribution costs $(-2.77)$. We proceed in two steps.

First, accept provisionally that the production and distribution cost figure is accurate. We can then examine the critical locus of values of $\bar{x}$ and $\bar{y}$ that make the mandatory deposit system exactly as socially desirable as the status quo (from an efficiency viewpoint). This locus is shown in Fig. $3{ }^{82}$ and the regions labeled "accept" and "reject" indicate where positive and negative net social benefits emerge for mandatory deposits. If $\bar{y}$ is as low as 0.78 cents per returned container, then the system of mandatory deposits would be preferred in an efficiency sense even if there were no willingness-to-pay for reduced container litter. And if $\bar{x}$ were as high as $\$ 27.12$ per Michigander per year, then mandatory deposits would be preferred no matter how high the time-of-return cost. I strongly suspect that neither of these is true: if $\bar{y}$ were below one cent, one would have to press Kahn's "tyranny of small decisions" logic [17] too hard to explain the dramatic shift away from returnable bottles since the $1950 \mathrm{~s}$; and a glance at the public budgets of Michigan suggests that its citizens would not devote a quarter billion dollars to a program promising a $62-85 \%$ reduction in beverage container litter. ${ }^{83}$ Whether a change to mandatory deposits is desirable for Michigan from an efficiency viewpoint is therefore debatable. One's opinion depends largely upon one's feeling for the unknown values of $\bar{x}$ and $\bar{y}$.

The impact of different estimates of the production and distribution costs on the critical locus is indicated in Fig. 4. These costs are raised and lowered by $25 \%$ of the basic value $(2.77 \phi / f)$ - to 3.46 and $2.08 \phi / f$-and the locus redrawn between values of $\bar{x}$ and $\bar{y}$ which represent social indifference between mandatory deposits and the status quo. These are not trivial shifts-the locus is thereby moved from one side to another of many people's subjective estimates of $\bar{x}$ and $\bar{y}$.

\footnotetext{
82 The equation of the locus is derived by setting the net benefit of mandatory deposits (i.e., the bottom line of Table $\mathrm{V}$ ) equal to zero.

${ }^{83}$ I.e. $\$ 247$ million $=(9.1$ million population $)(\$ 27.12)$.
} 


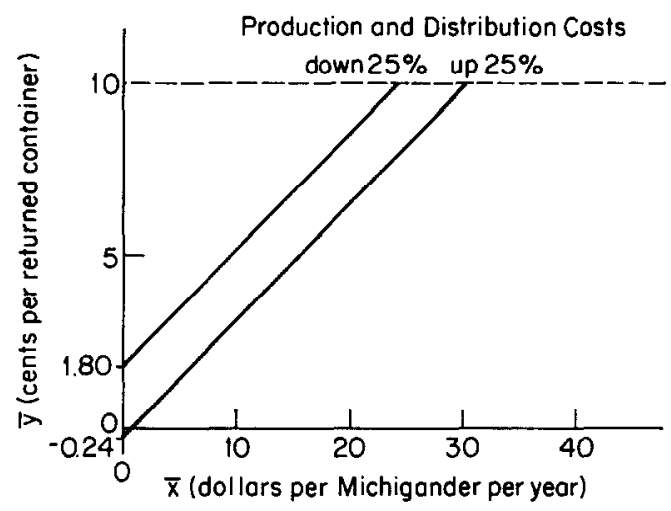

FIa. 4. Alternate estimates of production and distribution costs.

It is even more evident that reasonable men can disagree on whether mandatory beverage container deposits will pass or fail the efficiency test.

Up to now, no special treatment has been accorded either the energy or the employment aspects of the mandatory deposit system, despite the fact that they preoccupy well over half the now massive literature on the subject. ${ }^{84}$ In a social evaluation of this, as any other, policy, the use of energy or labor is regarded as a cost; and conversely, the saving of energy or labor is regarded as a benefit. One of the principal benefits of mandatory deposits is clearly the reduction in container costs (Section 5), and these occur primarily because of reductions in raw material and energy usage. And employment changes have entered throughout, as benefits when labor costs are reduced, as in litter pickup and solid waste collection (Sections 3 and 4), and as costs when more labor is required, whether paid as in beverage distribution (Section 6) or unpaid, as in the time of consumers to return "empties" (Section 7).

Furthermore, any change in energy use or employment has been entered here at the market price, reflecting both the economist's neoclassical faith that the price of a resource equals its marginal social opportunity cost and the pragmatist's recognition that no alternative measure of opportunity cost is readily available.

Much of the outpouring of concern for "jobs" and "energy" stems undoubtedly from one of three sources, a fundamental misunderstanding of economics, an excessive concern for the short run, or a proper introduction of social goals other than efficiency into the analysis. This is not the place for discussion of any of these. Nevertheless, there remains one very good reason why energy and employment might require special treatment, even within the efficiency scope of this evaluation: the prices of some factors may not equal their social opportunity costs. This suspicion is particularly strong with regard to labor and energy. Minimum wage regulations may have created a perpetual pool of unemployed, unskilled teenagers, in which case, the employment of a low-skill worker does not imply foregone output elsewhere at all (or certainly not to the extent of the minimum wage which that worker must be paid). Imperfect foresight, tax

${ }^{84}$ For examples, three of the four substantive chapters in [28], and two of the six in [6]; [34] devoted more pages to "energy and resource considerations" (pp. 74-103) than to "economic impacts" (pp. 49-73), and most of the latter is concerned with jobs and payrolls; in [3], "conservation of resources" is the first of three "rationales" for a beverage container policy. 
TABLE VI

Estimated Energy Consumption in Beverage Delivery in Michigan, 1974

A. Energy Consumption (in Trillion BTU's)

\begin{tabular}{|c|c|c|c|c|c|c|}
\hline \multicolumn{2}{|c|}{ Energy source } & Actual & \multicolumn{2}{|c|}{$\begin{array}{l}\text { With mandatory } \\
\text { deposits }\end{array}$} & \multicolumn{2}{|c|}{ Difference } \\
\hline \multirow{4}{*}{\multicolumn{2}{|c|}{$\begin{array}{l}\text { Fuel oil } \\
\text { Gasoline and diesel fuel } \\
\text { Gas } \\
\text { Coal }\end{array}$}} & 1.92 & \multicolumn{2}{|c|}{1.31} & 0.61 & \\
\hline & & 1.92 & \multirow{2}{*}{\multicolumn{2}{|c|}{$\begin{array}{l}1.31 \\
2.62\end{array}$}} & 0.61 & \\
\hline & & 11.52 & & & 8.90 & \\
\hline & & 3.84 & \multicolumn{2}{|c|}{1.31} & 2.53 & \\
\hline \multicolumn{2}{|l|}{ Total } & 19.21 & \multicolumn{2}{|c|}{6.54} & \multicolumn{2}{|l|}{12.67} \\
\hline \multicolumn{7}{|c|}{ B. Energy Consumption (in Natural Units) } \\
\hline Energy source & \multicolumn{2}{|c|}{ Units } & Actual & \multicolumn{2}{|c|}{$\begin{array}{l}\text { With mandatory } \\
\text { deposits }\end{array}$} & Difference \\
\hline Fuel oil & \multicolumn{2}{|c|}{ Thousand barrels } & 331.0 & \multicolumn{2}{|c|}{225.8} & 105.2 \\
\hline Gasoline and diesel fucl & \multicolumn{2}{|c|}{ Million gallons } & 14.77 & \multicolumn{2}{|c|}{10.08} & 4.69 \\
\hline Gas & \multicolumn{2}{|c|}{ Billion cubic feet } & 11.16 & \multicolumn{2}{|c|}{2.54} & 8.62 \\
\hline Coal & \multicolumn{2}{|c|}{ Thousand tons } & 192.0 & \multicolumn{2}{|c|}{65.5} & 126.5 \\
\hline
\end{tabular}

Sources: For composition of the Btu energy consumption, see [11, p. 40]; for conversion to natural units, see $[6$, p. 34$]$. Summation errors due to rounding.

distortions, and divergences between private and social time preference rates may have led to the overrapid depletion of our cheap fossil-fuel supplies, in which case the social opportunity cost, or user cost, is in fact much in excess of the observed current market price for such fuels. The remainder of this section seeks to discover what impact these considerations have on our analysis of mandatory deposits.

1. Energy. Refillable bottles that average 15 trips make a much smaller energy demand per trip than one-way containers. The refillable bottle consumes 18.44 million Btu's of energy per 1000 gallons of beer delivered, while the energy consumption of nonrefillable bottles is 64.38 million Rtu's, of steel-and-aluminum cans is 53.73 million Btu's, and of all-aluminum cans is 75.03 million Btu's. ${ }^{85}$ The switch contemplated here, for Michigan in 1974, from the present beveragedelivery system to one which only uses 15-trip refillable bottles, would reduce energy consumption from 19.21 trillion (10 $\left.10^{12}\right)$ Btu's, to 6.54 trillion Btu's, a saving of 12.67 trillion Btu's. ${ }^{86}$ These aggregate energy savings are broken down, in Table VI, into the savings of fuel oil, gasoline and diesel fuel, gas, and coal. The largest savings are on natural gas and coal, but the transport-intensive refillable system still manages to reduce consumption of gasoline and diesel fuel by nearly one third.

The market value of these energy savings has already been considered, largely in the reduced container cost per filling (Section 5). What must now be considered

${ }^{85} \mathrm{Btu}$ is a standard measure of energy, the British thermal unit. Data source: [16, p. 21]. The figure for 15 trips is interpolated from their estimates for 10 and 19 trips.

${ }^{86}$ I.e., a saving of $66 \%$. The figures for the present system ignore recycling. Source: [28, pp. $271,277]$. 
TABLE VII

Value of Energy Savings Due to Mandatory Deposits in Michigan, 1974

\begin{tabular}{|c|c|c|c|}
\hline Energy source & $\begin{array}{l}\text { Quantity of energy } \\
\text { saving }\end{array}$ & Price & $\begin{array}{c}\text { Value of } \\
\text { energy saving }\end{array}$ \\
\hline Fuel oil & 105.2 thousand barrels & $\$ 13.02 /$ barrel & $\$ 1.369$ million \\
\hline Gasoline and diesel fuel & 4.69 million gallons & $\$ 0.45 /$ gallon & $\$ 2.110$ million \\
\hline Gas & 8.62 billion cubic feet & $\$ 0.50 /$ thousand cubic feet & $\$ 4.310$ million \\
\hline \multirow[t]{2}{*}{ Coal } & 126.5 thousand tons & $\$ 26.00 /$ ton & $\$ 3.289$ million \\
\hline & & Total & $\$ 11.078$ million \\
\hline
\end{tabular}

Sources: Table VI, and [6, pp. 42, 114].

is the excess of social opportunity cost above market price. Quite arbitrarily, choosing high in order to glimpse the maximum effect, let us assume that the social opportunity cost of all energy sources is exactly twice the market price- e.g., a barrel of fuel oil was really worth $\$ 26.04$ per barrel rather than its market price of $\$ 13.02 .{ }^{87}$ This means that the value of the energy sources saved due to mandatory deposits must be counted as benefits a second time to reflect the divergence of social from private cost. This is done in Table VII. The tolal, and hence the benefit that must be attributed to mandatory deposits, is $\$ 11.078$ million. Put on a per filling basis, this is $0.28 \phi / f^{88}$-not very large, despite the assumption of a very large excess of social over private cost to energy.

In terms of the critical locus of values of $\bar{y}$ and $\bar{x}$ that yield exactly zero net benefit to mandatory deposits (Table $V$ ), these hypothetical energy considerations move the locus from $\bar{y}=+0.78+0.34 \bar{x}$ to $\bar{y}=+1.19+0.34 \bar{x}$. The shift is displayed in Fig. 5: the lowest upward-sloped line (labeled A) is the critical locus when there is no energy shadow-pricing; the next lowest line (B) is the locus when the social cost of energy is assumed to be double the market price.

Clearly, any plausible divergence of social and private cost of energy sources should change few opinions about the net benefit of mandatory deposits.

2. Employment. The additional labor that would be required under a system of muandatory deposits is largely low-skill labor-sorting, collecting, transporting, and washing refillable bottles. Particularly, the new labor at the retail level is likely to be drawn from the ranks of the teenaged, the low-skilled, and the unemployed. Let us make the probably extreme assumption that all new retail labor, but only retail labor, has a social opportunity cost of zero. This means that the added distribution cost of refillables is, from a social viewpoint, reduced by the market cost of retailer labor, which was estimated at 1.00 cents per additional returned bottle. This lowers the distribution costs of the all-refillable system by $0.68 \notin / f$ (Section 6). This in turn moves the critical locus (in Fig. 5) from $\bar{y}$ $=+0.78+0.34 \bar{x}$ (the line labeled $\mathrm{A}$ ) to $\bar{y}=+1.78+0.34 \bar{x}$ (the line labeled C)-about twice as much shift in the intercept as in the energy shadow-pricing exereise.

${ }^{87}$ The market price data are all for Minnesota in late 1973 [6, p. 42].

${ }^{88}$ The figure implicit in $[6$, pp. 9-10, $40 \mathrm{ff}]$ for Minnesota was $0.11 \% / f$, i.e., $(\$ 2.13$ million $(100) \div(1.85$ billion $\mathrm{f})$. But they assumed a social cost of energy only $32 \%$ above the market price; for the $100 \%$ excess considered here, they imply a benefit of $0.36 \notin / f$. 
especially concern for income distribution and employment. All of these are important considerations, but they should be complementary to, and not included in, an efficiency-oriented social benefit-cost analysis. ${ }^{2}$

The analysis here is an appraisal of Michigan's "bottle law" from the viewpoint of the welfare of Michiganders. Considered in detail (in Sections 3-7) are the five principal sources of changes in social benefits and costs: (i) litter (both pickup and "eyesore" costs); (ii) solid waste; (iii) containers; (iv) production and distribution; and (v) consumer convenience. For the first three, mandatory deposits result in reduced social costs (or increased social benefits), while for the last two, in increased social costs. These components are then added together (in Section 8), and the possible divergence of social and private costs of energy and employment are considered.

Whether mandatory deposits pass or fail this social test depends critically on one's evaluation of (i) the average value of the time it takes consumers to return empty containers, and (ii) the average value of the "eyesore" benefit to Michiganders of dramatically reduced (i.e., by around three-fourths) beverage container litter. If the average time cost of returning each "empty" is as low as one cent, then the average "eyesore" benefit need only be above $\$ 0.65$ per year per Michigander for the switch to mandatory deposits to be an efficient change. On the other hand, if the average time cost is five cents per "empty," then the average annual "eyesore" benefit must exceed $\$ 12.48$ per capita if mandatory deposits are to represent an improvement over the status quo. People's estimates of these values can vary greatly, and for many, the estimates fall close to these critical thresholds. It is not clear that, from an efficiency viewpoint alone, a system of mandatory deposits is either better or worse than the status quo. The decisive factor, for most people, is how a mandatory deposit system satisfies goals other than efficiency.

\section{METHODS AND ASSUMPTIONS}

Social evaluation requires the summation of the present value of the time stream of net benefits (i.e., benefits minus costs) due to a shift from the present beverage delivery system to the system which would emerge under mandatory deposits. With mandatory deposits, three kinds of changes can be envisioned: (i) the total consumption of beer and soft drinks might change; (ii) there would be a shift in the mix of containers, from cans to bottles, from "one-ways" to refillables; and (iii) the average number of fillings per refillable bottle might change. In this section, the evidence about these is examined, and the assumptions underlying the remainder of the paper are made explicit.

If mandatory deposits nonmarginally affected the consumption rates of beer and soft drinks, we would need to consider the consumer willingness-to-pay and the producer costs of the increased or decreased beverage output. And as the container mix shifts away from cans and one-way bottles toward returnable, and returned, bottles, two things happen that can affect consumption: a loss of

solid waste came to just $\$ 176$ million, it would appear that the ban's annual sacrifice of $\$ 800$ million in tax revenues makes it an expensive way to purchase relatively small reductions in roadside litter and solid waste.

${ }^{2}$ For a contrary view, that benefit-cost analysis can and should consider goals other than efficiency, see Dasgupta et al. [5]. 
If $r=14 / 15$ (see Section 2) and $d=10 \notin$, then $p^{\prime}>p$ if $c>0.71 \notin$. Considering that the costs to the retailer alone of collecting each empty container is estimated to be $0.76 \notin$ (see Section 6 ), it is quite clear that $c$ will be greater than $0.71 \&$, and hence that the price of beverages in one-way containers must rise. ${ }^{90}$

\section{APPENDIX 2. THE OPTIMAL FREQUENCY OF LITTER PICKUP}

A small model is sufficient to indicate that the direction of change in the optimal rate of litter pickup is not clear when the rate of littering declines.

Let the total pickup cost (TPC) of a particular area be an additive, linear function of the number of times per year that the litter is (completely!) picked up $(N)$ and the total volume of litter per year $(k$, where $k$ is the constant rate of littering per year). Thus, ${ }^{91}$

$$
\mathrm{TPC}=\alpha N+\beta k .
$$

The average volume of litter (AVL) to which the eyes of passersby are subjected is half the total volume of litter at the time of pickup:

$$
\mathrm{AVL}=k / 2 N \text {. }
$$

The total amenity cost of litter (TAC) is a function of this average volume of litter, i.e.,

$$
\mathrm{TAC}=A(k / 2 N)
$$

where $A(\cdot)$ is a function whose derivative $\left(A^{\prime}\right)$ is clearly positive. The sign of the second derivative $\left(A^{\prime \prime}\right)$ is not certain. $A^{\prime \prime}$ is probably positive in the region around $\mathrm{AVL}=0$, but it may well become negative at high levels of AVI-i.e., once the eyes are inured to litter, further additions may yield still positive but declining marginal disutility.

The optimal periodicity of litter pickup requires that the sum of these two costs be minimized with respect to $N$ :

$$
(\mathrm{TPC}+\mathrm{TAC})=\alpha N+\beta k+A(k / 2 N) .
$$

This minimization occurs where

$$
\alpha-k A^{\prime} / 2 N^{2}=0,
$$

which yields a single interior solution provided that

$$
4 N A^{\prime}+k A^{\prime \prime}>0
$$

for all $N$. Note that this last condition does not require that $A^{\prime \prime}$ be positive at the point of cost minimization.

Clearly, from Eq. (2-5), the optimal rate of pickup $(N)$ will be affected by the rate of litter $(k)$. Taking derivatives, we find that

$$
d N / d k \gtrless 0 \quad \text { as } 2 N A^{\prime}+k A^{\prime \prime} \gtrless 0 .
$$

${ }^{90}$ Implicit in this are the assumptions that (1) the profit margin on beverages in such containers does not change, (2) container recycling remains economically costly relative to disposal, and (3) the bottler is permitted to retain unredeemed deposits. Note especially this third assumption. If the state claims unredeemed deposits (as Michigan is considering doing), its action is effectively a new tax on beverages of roughly two thirds of a cent per container (i.e., the 10 cent deposit rate divided by the trippage, 15).

${ }^{11}$ Where it is being assumed that the $N$ pickups are regularly spaced. $\alpha$ and $\beta$ are cost function parameters. 
Comparison of the conditions (2-6) and (2-7) reveals that there is a range of negative values of $A^{\prime \prime}$ that satisfies (2-6) and nevertheless makes $d N / d k$ negative. In this range, reduced litter rates imply more frequent litter pickup. Moreover, it is not impossible that the optimal rate of pickup is independent of the litter rate..$^{92}$

\section{REFERENCES}

1. Alcoa, "Trouble on the Oregon Trail," no date.

2. Applied Decision Systems (ADS), "Study of the Effectiveness and Impact of the Oregon Minimum Deposit Law" (Oct. 1974).

3. T. H. Bingham and P. F. Mulligan, "The Beverage Container Problem : Analysis and Recommendations," Research Triangle Institute (Sept. 1972).

4. B. Branch, The economics of reusable bottles, Wall Street Journal (20 April 1972) (reprinted in Hearings (1972), 482-483).

5. P. Dasgupta, S. Marglin, and A. Sen, "Guidelines for Project Evaluation," U. N. Industrial Development Organization (1972).

6. R. Dildine and R. Rainey, "Impacts of Beverage Container Regulation in Minnesota," Minnesota Council of Economic Advisors and Minnesota State Planning Agency (January 1974).

7. K. G. Elzinga, The beer industry, in "The Structure of American Industry" (W. Adams, Ed.), Chap. 6, Macmillan, London, 1977.

8. E.P.A., "Third Report to Congress : Resource Recovery and Waste Reduction" (1975).

9. A. L. Finkner, "National Study of The Composition of Roadside Litter," Research Triangle Institute (1969).

10. C. Gudger and J. C. Bailes, "The Economic Impact of Oregon's Bottle Bill," Oregon State University (March 1974).

11. B. Hannon, "System Energy and Reeycling: A Study of the Beverage Industry," Center for Advanced Computation, University of Illinois (January 1972).

12. C. B. Harris, "The Environment and Packaging: An Economic and Legislative Analysis," reprinted in Hearings (1972), 132-170.

13. Hearings before the Senate Subcommittee on the Environment on S. 1377 and S. 3058, 6-13 March 1972.

14. Hearings before the Senate Subcommittee on the Environment on S. 2062, 6-7 May 1974.

15. Hearings before the House Subcommittee on Transportation and Commerce on H.R. 5487 and 406, 8-17 April 1975.

16. R. G. Hunt et al., "Resource and Environmental Profile Analysis of Nine Beverage Container Alternatives," E.P.A. (1974).

17. A. E. Kahn, The tyranny of small decisions: Market failures, imperfections, and the limits of economics, Kyklos, Fasc. 1 (1966).

18. R. W. Kopcke, The economic effects of requiring deposits on beverage containers, New England Econ. Indicators (March 1976).

19. League of Women Voters, "Environmental Update on Solid Waste Management" (JanuaryFebruary, 1974).

20. J. Leigh and M. R. Warshaw, The Michigan bottle bill: Will consumers put their money where they put their votes?, Univ. of Michigan Business Rev. (Nov. 1977).

21. M. Loube, "The Vermont Experience," U.S. Environmental Protection Agency (1975).

22. E. F. Lowry, T. W. Fenner, and R. M. Lowry, "Disposing of Non-Returnables: A Guide to Minimum Deposit Legislation," Stanford Environmental Law Society (January 1975).

23. J. Maillie, "The National Economic Impact of a Ban on Non-Refillable Beverage Containers," Midwest Research Institute (June 1971).

24. B. F. Massell and R. M. Parish, Empty bottles, J. of Political Econ. 76 (1968).

25. P. Murphy, A cost-benefit analysis of the Oregon "Bottle Bill," American Marketing Association, Combined Proceedings, Series No. 36 (Spring/Fall 1974).

26. Office of Business and Legislative Issues, "The Impacts of National Beverage Container Legislation," Department of Commerce (1975).

${ }^{92}$ For example, if $\mathrm{TAC}=\log \gamma(\mathrm{AVL})^{8}$. 
27. D. Pinsky, "Pricing Aspects of Container Deposit Legislation on Beverages," University of Connecticut Labor Education Center (January 1977).

28. G. B. Rao, "An Economic Analysis of Energy and Employment Effects of Deposit Regulation on Non-Returnable Beverage Containers in Michigan," Michigan Public Service Commission (October 1975).

29. J. F. Savage and H. R. Richmond III, "Oregon's Bottle Bill: A Riproaring Success," Oregon Student Public Interest Research Group (May 1974).

30. T. Scitovsky, "The Joyless Economy," Oxford Univ. Press, London, 1976.

31. L. Seddon to J. Parry, letter, Vermont Public Interest Research Group, Montpelier, Vermont (17 December 1976).

32. E. Selby and M. Selby, Can this law stop the trashing of America?, Readers' Digest (March 1976).

33. Small deposit, big return, Michigan Natural Resources (November-December 1974).

34. Task Force on Critical Problems, New York State Senate, "No Deposit, No Return: A Report on Beverage Containers"' (February 1975).

35. Tin Mill Products Producers, "Restrictive Container Legislation in the United States" (no date) (printed in Hearings (1975), 226-235).

36. L. H. Tribe, C. S. Schelling, and J. Voss, "When Values Conflict," Ballinger, Cambridge (1976).

* 37. D. Waggoner, "Oregon's Bottle Bill--Two Years Later," Columbia Group Press (1974).

38. R. N. Williams, The trashing of America, New Times (3 May 1974). 